\title{
Pengaruh Kualitas Sistem Pencatatan dan Pelaporan Terpadu Puskesmas (SP2TP) Terhadap Tata Kelola Administrasi
}

\author{
Maximilianus Dasril Samura $^{(1)}$, Novrika Silalahi ${ }^{(2)}$ \\ Institut Kesehatan Deli Husada Deli Tua \\ coknasamura@gmail.com (1), novrikasilalahi29@gmail.com (2)
}

\begin{abstract}
ABSTRAK
Puskesmas sering mengalami keterlambatan dalam pengiriman laporan bulanan Sistem Pencatatan dan Pelaporan Terpadu Puskesmas (SP2TP) oleh petugas Puskesmas. Hal ini disebabkan karena kurangnya peran faktor internal Puskesmas dalam hal ketersediaan data, SDM (Sumber Daya Manusia) serta peralatan dalam upaya mencapai kelengkapan dokumen SP2TP di Puskesmas. Bahkan tidak jarang juga koordinator di Puskesmas ikut serta dalam menginput data, padahal tugasnya mengkoordinir anggotanya untuk dapat melakukan pelaporan dengan baik. Banyak puskesmas telah memiliki komputer tetapi tidak digunakan dalam pengerjaan untuk laporan SP2TP, karena sudah terbiasa dengan cara manual yaitu mencatat setiap laporan kedalam buku laporan bulanan. Padahal informasi atau laporan haruslah mempunyai kualitas yang relevan, tepat waktu dan efisien agar dapat bermanfaat bagi yang membutuhkan sebagai dasar pengambilan keputusan, sehingga kemungkinan tidak terjadi kesalahan baik yang disengaja maupun yang tidak di sengaja. Tujuan dari penelitian ini adalah untuk menganalisis pengaruh sistem pencatatan dan pelaporan terpadu Puskesmas (SP2TP) terhadap tata kelola administrasi di wilayah kerja Puskesmas Biru- biru Kabupaten Deli Serdang. Penelitian ini merupakan penelitian survei yang bersifat explanatory dengan menggunakan pendekatan cross sectional yaitu penelitian yang akan menggali, menganalisa dan menjelaskan tentang kualitas sistem pencatatan dan pelaporan terpadu terhadap tata kelola administrasi di wilayah kerja Puskesmas Biru-biru Kabupaten Deli Serdang Tahun 2019. Dalam pengumpulan data, data diperoleh dari seluruh tenaga kesehatan yang ada di Puskesmas Biru-biru melalui wawancara langsung dengan menggunakan instrumen (kuesioner) dan observasi mendalam, maupun dari catatan Puskesmas Biru-biru. Dari hasil penelitian diperoleh bahwa kualitas SDM, kehandalan dan daya tanggap dalam melaksanakan SP2TP berpengaruh terhadap tata kelola di Puskesmas Sibiru-biru. Sedangkan faktor pendanaan tidak berpengaruh terhadap tata Kelola administrasi.
\end{abstract}

Kata Kunci : Sistem, Pencatatan, Pelaporan, Puskesmas, Tata kelola

\begin{abstract}
Puskesmas often experience delays in sending monthly reports of the Puskesmas Integrated Recording and Reporting System (SP2TP) by Puskesmas officers. This is due to the lack of role of Puskesmas internal factors in terms of data availability, human resources (Human Resources) and equipment in an effort to achieve completeness of the SP2TP documents at the Puskesmas. In fact, it is not uncommon for the coordinator at the Puskesmas to participate in inputting data, even though it is his job to coordinate the members to be able to report properly. Many puskesmas already have computers but they are not used in the work for SP2TP reports, because they are familiar with the manual method, which is to record each report into a monthly report book. In fact, information or reports must be of relevant, timely and efficient quality so that they can be of use to those in need as a basis for decision making, so that there is no possibility of mistakes, whether intentional or accidental. The purpose of this study was to analyze the effect of the Integrated Public Health Center (SP2TP) recording and reporting system on administrative governance in the work area of Puskesmas Biru-Biru, Deli Serdang Regency. This research is an explanatory survey research using a cross sectional approach, namely research that will explore, analyze and explain the quality of the integrated recording and reporting system on administrative governance in the work area of Puskesmas Biru-Biru, Deli Serdang Regency in 2019. In data collection, The data were obtained from all health personnel in the Biru-Biru Puskesmas through direct interviews using instruments (questionnaires) and in-depth observations, as well as from the records of the Biru-Biru Puskesmas. From the research results, it was found that the quality of human resources, reliability and responsiveness in implementing SP2TP had an effect on governance at Puskesmas Sibiru-Biru. Meanwhile, the funding factor has no effect on administrative governance.
\end{abstract}

Keywords : System, Recording, Reporting, Puskesmas, Governance 
Dasril Samura M, Silalahi N : Pengaruh Kualitas Sistem Pencatatan dan Pelaporan Terpadu Puskesmas (SP2TP) Terhadap Tata Kelola Administrasi

\section{PENDAHULUAN}

\section{Latar Belakang}

Di era globalisasi saat ini, masyarakat membutuhkan sebuah layanan publik yang bermutu dari pemerintah daerah khusunya dalam pelayanan kesehatan. Jika hal ini dapat terpenuhi, niscaya kepercayaan publik terhadap Pemerintah Daerah akan meningkat, karena mereka merasa puas dapat mengakses pelayanan yang mereka butuhkan. Selama ini stigma yang timbul di masyarakat terhadap pelayanan publik adalah kurang mampu bersaing dengan swasta, kurang transparan, tatakelola kurang baik, pendanaan terbatas, sumber daya manusia kurang memadai dan disiplin rendah. Tenaga kesehatan juga sering mengeluh tentang banyaknya pekerjaan yang harus mereka lakukan, sehingga beberapa keluhan dan kejadian yang terjadi di masyarakat tidak terdokumentasi dengan baik. Inilah yang akan menimbulkan berbagai dampak yang buruk terhadap pengelolaan Puskesmas khususnya dalam pemberian layanan yang bermutu, juga dalam melakukan upaya pencegahan terhadap penyakit. Tidak jarang Puskesmas mengalami keterlambatan dalam pengiriman laporan bulanan SP2TP oleh petugas puskesmas, karena kurangnya peran faktor internal puskesmas dalam hal ketersediaan data, sumber daya manusia (SDM) serta peralatan dalam upaya mencapai kelengkapan dokumen SP2TP. Hampir di setiap Puskesmas telah memiliki komputer tetapi tidak digunakan dalam pengerjaan untuk laporan SP2TP, karena kurangnya peran faktor eksternal dari Dinas Kesehatan dalam upaya kelengkapan dokumen SP2TP berupa pembinaan dan pengawasan di Puskesmas. Dan pelaksanaan SP2TP di Puskesmas masih belum lengkap sesuai dengan struktur perencanaan, pelaksanaan, dan evaluasinya. Hal ini menunjukkan adanya bebagai kesulitan yang sedang dihadapi baik, pengelola SP2TP maupun pengelola program di Puskesmas, sehingga pengumpulan dokumen SP2TP belum lengkap, juga belum tersedianya buku pedoman tentang SP2TP di Puskesmas.

\section{Perumusan Masalah}

Puskesmas sebagai pusat pelayanan kesehatan dasar, pusat penggerak, dan pusat pemberdayaan masyarakat harus dapat didayagunakan seefektif mungkin, agar sistem informasi kesehatan dapat berjalan dengan baik. Puskesmas Biru-biru merupakan salah satu Puskesmas yang ada di Kabupaten Deli Serdang yang memiliki wilayah kerja cukup luas. Saat dilakukan pendekatan kepada masyarakat, mereka cenderung merasa kurang puas dengan pelayanan yang diberikan oleh tenaga kesehatan. Hal ini terjadi karena tenaga kesehatan yang jarang bahkan tidak pernah memberikan informasi terkait dengan penyakit atau keluhan yang dialami masyarakat ketika melakukan kunjungan ke Puskesmas.

\section{Tujuan Penelitian}

Penelitian ini bertujuan yaitu :

Melihat dan mendapatkan data dilapangan dan menganalisis bagaimana pengaruh kualitas sistem pencatatan dan pelaporan terpadu puskesmas (SP2TP) terhadap tata kelola administrasi pelayanan kepada masyarakat.

\section{Manfaat Penelitian}

Dengan adanya penelitian ini diharapkan mampu memperbaiki animo masyarakat terhadap kualitas pelayanan dan SDM di tata kelola administrasi Puskesmas sehingga masyarakat tidak lagi merasa kurang puas atau kecewa terhadap pelayanan yang diberikan.

\section{METODE PENELITIAN}

Jenis penelitian ini adalah penelitian survei bersifat explanatory dengan pendekatan cross sectional yaitu penelitian menggali, menganalisa dan menjelaskan bagaimana pengaruh sistem pencatatan dan pelaporan terhadap tata kelola administrasi. Responden dalam 
Dasril Samura M, Silalahi N : Pengaruh Kualitas Sistem Pencatatan dan Pelaporan Terpadu Puskesmas (SP2TP) Terhadap Tata Kelola Administrasi

penelitian ini adalah Kepala Puskesmas, staf di bagian administrasi, bagian keuangan, bidan desa, perawat, serta bagian lain yang diperbantukan dalam pengurusan program, total sebanyak 70 orang. Data yang telah diperoleh dari proses pengumpulan data (baik data sekunder dan data primer) ataupun dengan menggunakan kuesioner, kemudian dibahas untuk dipaparkan keadaan yang ditemui berdasarkan teori-teori pendukung kemudian di lakukan analisis data sebagai berikut: Analisis univariat digunakan pada tiap-tiap variabel hasil penelitian untuk mengetahui hasil yang nantinya akan digunakan sebagai tolak ukur pembahasanya dan kesimpulan, kemudian dilakukan analisis deskriptif, menggunakan formula : $\mathrm{F}=\mathrm{P} / \mathrm{N}$. ( $\mathrm{P}=$ Persentase, $\mathrm{F}=$ jawaban, $\mathrm{N}=$ Jumlah pertanyaan). Selanjutnya dilakukan Analisis Bivariat, untuk menguji ada tidaknya hubungan variabel independen dan dependen, penulis menggunakan uji Chi-Square dengan taraf signifikan 95\% $(0,05)$. Kemudian dilakukan analisis multivariat dilakukan untuk mengetahui pengaruh antara variabel independen dengan variabel dependen sehingga diketahui variabel mana yang paling dominan terhadap variab.el dependen dengan menggunakan analisis regresi logistik mempergunakan komputer.

\section{HASIL PENELITIAN}

Hasil Penelitian adalah sebagai berikut :

Tabel. 1 Pengaruh Pendanaan Terhadap Tata Kelola Administrasi

\begin{tabular}{|c|c|c|c|c|c|c|c|}
\hline & & & \multicolumn{3}{|c|}{ Pendanaan } & \multirow[b]{2}{*}{ Total } & \multirow[b]{2}{*}{ P-value } \\
\hline & & & Baik & Cukup & Kurang & & \\
\hline \multirow{4}{*}{$\begin{array}{l}\text { Tata } \\
\text { Kelola }\end{array}$} & \multirow[t]{2}{*}{ Baik } & Count & 4 & 9 & 4 & 17 & \multirow{6}{*}{0,508} \\
\hline & & $\%$ of Total & $5.7 \%$ & $12.9 \%$ & $5.7 \%$ & $24.3 \%$ & \\
\hline & \multirow{2}{*}{$\begin{array}{l}\text { Tidak } \\
\text { Baik }\end{array}$} & Count & 19 & 20 & 14 & 53 & \\
\hline & & $\%$ of Total & $27.1 \%$ & $28.6 \%$ & $20.0 \%$ & $75.7 \%$ & \\
\hline \multirow{2}{*}{\multicolumn{2}{|c|}{ Total }} & Count & 23 & 29 & 18 & 70 & \\
\hline & & $\%$ of Total & $32.9 \%$ & $41.4 \%$ & $25.7 \%$ & $100.0 \%$ & \\
\hline
\end{tabular}

Berdasarkan tabel di atas diketahui bahwa dari 17 responden $(24,3 \%)$ yang menyebutkan bahwa tata kelola baik sebanyak 4 orang $(5,7 \%)$ pendanaan baik, 9 orang $(12,9 \%)$ pendanaan cukup, 4 orang $(5,7 \%)$ pendanaan kurang. Dari 53 orang yang menyebutkan tata kelola tidak baik $(75,7 \%), 19$ orang $(27,1 \%)$ menyatakan pendanaan baik, 20 orang $(28,6 \%)$ pendanaan cukup dan 14 orang (20\%) pendanaan kurang. Hasil analisis dengan menggunakan uji chi-square menunjukkan bahwa nilai p-value 0,508 $>0,05$, sehingga dapat disimpulkan bahwa pada penelitian ini tidak ada pengaruh Pendanaan dengan Tata Kelola Administrasi.

Tabel. 2 Pengaruh SDM Terhadap Tata Kelola Administrasi

\begin{tabular}{|c|c|c|c|c|c|c|c|}
\hline & & & \multicolumn{3}{|l|}{ SDM } & \multirow[b]{2}{*}{ Total } & \\
\hline & & & Baik & Cukup & Kurang & & \\
\hline \multirow{4}{*}{$\begin{array}{l}\text { Tata } \\
\text { Kelola }\end{array}$} & \multirow[t]{2}{*}{ Baik } & Count & 2 & 1 & 14 & 17 & \multirow{6}{*}{0,003} \\
\hline & & $\%$ of Total & $2.9 \%$ & $1.4 \%$ & $20.0 \%$ & $24.3 \%$ & \\
\hline & \multirow{2}{*}{$\begin{array}{l}\text { Tidak } \\
\text { Baik }\end{array}$} & Count & 15 & 19 & 19 & 53 & \\
\hline & & $\%$ of Total & $21.4 \%$ & $27.1 \%$ & $27.1 \%$ & $75.7 \%$ & \\
\hline \multirow{2}{*}{\multicolumn{2}{|c|}{ Total }} & Count & 17 & 20 & 33 & 70 & \\
\hline & & $\%$ of Total & $24.3 \%$ & $28.6 \%$ & $47.1 \%$ & $100.0 \%$ & \\
\hline
\end{tabular}


Dasril Samura M, Silalahi N : Pengaruh Kualitas Sistem Pencatatan dan Pelaporan Terpadu Puskesmas (SP2TP) Terhadap Tata Kelola Administrasi

Berdasarkan tabel di atas diketahui bahwa dari 17 responden $(24,3 \%)$ yang menyebutkan bahwa tata kelola baik sebanyak 2 orang (2,9\%) SDM baik, 1 orang (1,4\%) SDM cukup, 14 orang (20\%) SDM kurang. Dari 53 orang yang menyebutkan tata kelola tidak baik $(75,7 \%)$, 15 orang $(21,4 \%)$ menyatakan SDM baik, 19 orang $(27,1 \%)$ SDM cukup dan 19 orang $(27,1 \%)$ SDM kurang.

Hasil analisis dengan menggunakan uji chi-square menunjukkan bahwa nilai p-value 0,003 $<0,05$, sehingga dapat disimpulkan bahwa pada penelitian ini ada pengaruh kualitas SDM dengan Tata Kelola Administrasi.

Tabel. 3 Pengaruh Kehandalan Terhadap Tata Kelola Administrasi

\begin{tabular}{|c|c|c|c|c|c|c|c|}
\hline & & & \multicolumn{3}{|c|}{ Kehandalan } & \multirow[b]{2}{*}{ Total } & \multirow[b]{2}{*}{ P-value } \\
\hline & & & Baik & Cukup & Kurang & & \\
\hline \multirow{4}{*}{$\begin{array}{l}\text { TataKelol } \\
\text { a }\end{array}$} & \multirow[t]{2}{*}{ Baik } & Count & 5 & 1 & 11 & 17 & \multirow{6}{*}{0,017} \\
\hline & & $\%$ of Total & $7.1 \%$ & $1.4 \%$ & $15.7 \%$ & $24.3 \%$ & \\
\hline & \multirow{2}{*}{$\begin{array}{l}\text { Tidak } \\
\text { Baik }\end{array}$} & Count & 18 & 19 & 16 & 53 & \\
\hline & & $\%$ of Total & $25.7 \%$ & $27.1 \%$ & $22.9 \%$ & $75.7 \%$ & \\
\hline \multirow{2}{*}{\multicolumn{2}{|c|}{ Total }} & Count & 23 & 20 & 27 & 70 & \\
\hline & & $\%$ of Total & $32.9 \%$ & $28.6 \%$ & $38.6 \%$ & $100.0 \%$ & \\
\hline
\end{tabular}

Berdasarkan tabel di atas diketahui bahwa dari 17 responden $(24,3 \%)$ yang menyebutkan bahwa tata kelola baik sebanyak 5 orang $(7,1 \%)$ Kehandalan baik, 1 orang $(1,4 \%)$ Kehandalan cukup, 11 orang $(15,7 \%)$ Kehandalan kurang. Dari 53 orang yang menyebutkan tata kelola tidak baik $(75,7 \%), 18$ orang $(25,7 \%)$ menyatakan Kehandalan baik, 19 orang $(27,1 \%)$ Kehandalan cukup dan 16 orang $(22,9 \%)$ Kehandalan kurang.

Hasil analisis dengan menggunakan uji chi-square menunjukkan bahwa nilai p-value 0,017 $<0,05$, sehingga dapat disimpulkan bahwa pada penelitian ini ada pengaruh Kehandalan dengan Tata Kelola Administrasi.

Tabel. 4 Pengaruh Daya Tanggap Terhadap Tata Kelola Administrasi

\begin{tabular}{|c|c|c|c|c|c|c|c|}
\hline & & & \multicolumn{3}{|c|}{ Daya Tanggap } & \multirow[b]{2}{*}{ Total } & \multirow[b]{2}{*}{$\mathrm{P}$-value } \\
\hline & & & Baik & Cukup & Kurang & & \\
\hline \multirow{4}{*}{$\begin{array}{l}\text { Tata } \\
\text { Kelola }\end{array}$} & \multirow[t]{2}{*}{ Baik } & Count & 8 & 1 & 8 & 17 & \multirow{6}{*}{0,001} \\
\hline & & $\%$ of Total & $11.4 \%$ & $1.4 \%$ & $11.4 \%$ & $24.3 \%$ & \\
\hline & \multirow{2}{*}{$\begin{array}{l}\text { Tidak } \\
\text { Baik }\end{array}$} & Count & 18 & 28 & 7 & 53 & \\
\hline & & $\%$ of Total & $25.7 \%$ & $40.0 \%$ & $10.0 \%$ & $75.7 \%$ & \\
\hline \multirow{2}{*}{\multicolumn{2}{|c|}{ Total }} & Count & 26 & 29 & 15 & 70 & \\
\hline & & $\%$ of Total & $37.1 \%$ & $41.4 \%$ & $21.4 \%$ & $100.0 \%$ & \\
\hline
\end{tabular}

Berdasarkan tabel di atas diketahui bahwa dari 17 responden $(24,3 \%)$ yang menyebutkan bahwa tata kelola baik sebanyak 8 orang $(11,4 \%)$ Daya Tanggap petugas baik, 1 orang $(1,4 \%)$ Daya Tanggap petugas cukup, 8 orang $(11,4 \%)$ Daya Tanggap petugas kurang. Dari 53 orang yang menyebutkan tata kelola tidak baik $(75,7 \%)$, 18 orang $(25,7 \%)$ menyatakan Daya Tanggap petugas baik, 28 orang (40\%) Daya Tanggap petugas cukup dan 7 orang (10\%) Daya Tanggap petugas kurang. 
Dasril Samura M, Silalahi N : Pengaruh Kualitas Sistem Pencatatan dan Pelaporan Terpadu Puskesmas (SP2TP) Terhadap Tata Kelola Administrasi

Hasil analisis dengan menggunakan uji chi-square menunjukkan bahwa nilai p-value 0,001 $<0,05$, sehingga dapat disimpulkan bahwa pada penelitian ini ada pengaruh Daya Tanggap dengan Tata Kelola Administrasi

\section{PEMBAHASAN}

a. Pendanaaan

Pendanaan merupakan salah satu sumber daya yang berpengaruh terhadap kinerja termasuk dalam tata kelola. Dana atau biaya merupakan sejumlah uang yang disediakan dan dipergunakan secara langsung untuk mencapai tujuan kegiatan. Fadlia (2012) menyatakan bahwa faktor keuangan merupakan sesuatu yang vital terhadap terlaksananya berbagai aktivitas pelayanan publik, karena dengan adanya dana dalam suatu organisasi dapat mempengaruhi perkembangan sebuah organisasi dalam memberikan pelayanan yang terbaik. Namun dalam hal pelaksanaan SP2TP di puskesmas tidak disediakan dana khusus oleh Dinas Kesehatan, sehingga dana yang selama ini dibutuhkan dalam pelakasanaan SP2TP berasal dari dana puskesmas, dan hal tersebut dirasakan masih memadai dalam melaksanakan SP2TP. Sehingga pendanaan tidak berpengaruh terhadap tata Kelola di puskesmas.

b. Sumber Daya Manusia (SDM)

Sebuah organisasi dalam pelaksanaannya mempunyai tujuan dan harapan berbeda-beda, dengan tujuan dan harapan tersebut dapat diraih melalui dukungan sumber daya yang dimiliki organisasi, tersedianya sumber daya memadai akan meningkatkan keunggulan dalam pelaksanaan kegiatan program pada organisasi (WHO,2008). Keberhasilan pelaksanaan SP2TP sangat ditentukan oleh faktor manusia yang melaksanakan prosedur sistem informasi. Pengetahuan dan keterampilan merupakan hal mendasar yang harus dimiliki oleh petugas dalam melaksanakan kegiatan sistem informasi kesehatan. Untuk itu, sudah seharusnya puskesmas perlu dibekali dengan sumber daya manusia yang kompeten dan handal, agar dapat melaksanakan kegiatan pencatatan dan pelaporan SP2TP secara efektif dan efisien.

c. Kehandalan

Pihak Puskesmas sudah seharusnya mengirimkan petugas SP2TP untuk mengikuti pelatihan khusus dalam meningkatkan kemampuannya mengelola pelaporan secara terpadu, sehingga data yang akan dikirimkan dapat dilaksanakan tepat waktu. Demikian juga dengan adanya tenaga khusus SP2TP, diharapkan akan lebih meningkatkan kualitas data pencatatan dan pelaporan SP2TP di Puskesmas.

d. Daya Tanggap

Daya tanggap merupakan sebuah respon yang diberikan oleh pemberi layanan dalam sebuah organisasi. Daya tanggap dapat juga dalam bentuk pemberian umpan balik sebagai sebuah kontrol dalam mengukur keluaran dari sistem informasi, yang bertujuan jika ada penyimpangan petugas dapat melakukan koreksi untuk menyesuaikan terhadap kelemahankelemahan dari laporan yang disampaikan. Kualitas data dan dampaknya terhadap sistem informasi harus dilihat dari perspektif yang luas tidak saja terfokus pada istilah teknis, seperti alat pengumpulan data dan sistem pelaporan, akan tetapi juga pada mekanisme pendukung lainnya, seperti proses umpan balik berkesinambungan dalam menghadapi permintaan data dengan tetap. Daya tanggap tidak dapat diabaikan dalam pelaksanaan komunikasi data SP2TP dikarenakan komunikasi akan efektif apabila petugas SP2TP segera memberikan umpan balik terhadap pengelolaan dan pelopran yg menyimpang. Daya tanggap dapat meningkatkan motivasi kerja petugas dalam melaksanakan tanggungjawab secara baik dan benar, sehingga akan berdampak juga terhadap pengelolaan puskesmas 
Dasril Samura M, Silalahi N : Pengaruh Kualitas Sistem Pencatatan dan Pelaporan Terpadu Puskesmas (SP2TP) Terhadap Tata Kelola Administrasi

\section{KESIMPULAN}

Berdasarkan temuan hasil penelitian ini didapatkan beberapa kesimpulan yaitu :

1. Bahwa pendanaan tidak berpengaruh terhadap tata kelola SP2TP

2. SDM wajib ditingkatkan dalam mencapai target pelaksanaan SP2TP yang efektif dan efisien

3. Sistem harus handal dalam menjaga kelangsungan proses SP2TP

4. Daya Tanggap sangat diperlukan dalam menjaga tanggung jawab dalam pelaksanaan SP2TP

\section{DAFTAR PUSTAKA}

Akuntabel Y, Bumd D, Milik B, Bina D, Daerah K, Negeri KD. Disampaikan Oleh : 2018. Choyriati. Pencatatan dan Pelaporan KB,. 2016. http://lailychoyriati.blogspot.co.id.

Herawati S, Purnomo M. Rancang bangun sistem informasi pencatatan dan pelaporan terpadu puskesmas. Multitek Indones. 2016; Vol 10(No 1):39-47.

KEPMENKES_1075_2003.pdf.

Notoatmodjo S. Promosi Kesehatan \& Ilmu Perilaku. 2010:184.

Prof.-Dr.-Sugiyono-Metode-Penelitian-Kuantitatif-Kualitatif-Dan-Rd.-Intro.Pdf.

Puspita SJ. Kajian Sistem Pencatatan Dan Pelaporan Terpadu Puskesmas (SP2TP) Wilayah Kerja Puskesmas Umbulsari Kabupaten Jember Tahun 2013. 2013;2013.

Reza B. ( SP2TP ) DENGAN EXTREME PROGRAMMING PADA KABUPATEN BREBES. 2012;VII(01):34-50.

Sari IR. Program Kesehatan Ibu Dan Anak Pada Dinas Kesehatan Kabupaten Kudus. Sist Inf PENCATATAN DAN PELAPORAN PUSKESMAS Progr Kesehat IBU DAN ANAK PADA DINAS Kesehat KABUPATEN KUDUS Intan. 2016;7(1):251-256.

Suwarsi Y. Analisis Fleksibilitas Pengelolaan Keuangan Pada Puskesmas Badan Layanan Umum Daerah (Kasus Dua Puskesmas di Kabupaten Banjar). Focus (Madison). 2018;8(1):163-194. https://msap-unlam.ac.id/download/jurnal_focus/05- YuliantiSuwarsi-ok.pdf.

Tuwongkesong F, Mandagi CKF, Kesehatan F, Universitas M, Ratulangi S. Sistem pencatatan dan pelaporan terpadu puskesmas ( SP2TP ) merupakan kegiatan dan pelaporan data umum, sarana , tenaga dan upaya pelayanan Kesehatan di masyarakat ( SK Menkes No kebijakan kesehatan tidak berdasarkan data yang akurat ( Kemenkes RI , 2011. 2016:1-8.

WHO. (2008). Framework and Standards for Country Health Information Systems. World Health.

Widaningtyas E. Kesiapan Tata Kelola Puskesmas Menjadi Badan Layanan Umum Daerah (Blud). J Manaj Inf Kesehat Indones. 2018;6(1):20. doi:10.33560/.v6i1.180

Widianto KP, Trisnantoro L, Padmawati RS. ( PPK-BLU ) PADA PROGRAM KESEHATAN JIWA MASYARAKAT PUSKESMAS DI KABUPATEN SLEMAN, APPLICATION OF FINANCIAL MANAGEMENT OF PUBLIC SERVICES AGENCY ( PPK-BLU ) IN, Sejak dikeluarkannya Keputusan Menteri Dalam Negeri No . 61 / 2007 tentang Pedoman Teknis Pe- Tek. 2015;04(02):44-49.

\begin{tabular}{|l|l|l|l|}
\hline Accepted Date & Revised Date & Decided Date & Accepted to Publish \\
\hline 27 November 2020 & 30 November 2020 & 04 Desember 2020 & Ya \\
\hline
\end{tabular}

